\title{
MICROCEPHALY IN ONE OF MONOZYGOUS TWINS
}

\author{
BY \\ M. G. W. BRANDON, BRIAN H. KIRMAN and C. E. WILLIAMS \\ From the Fountain Hospital, London
}

(RECEIVED FOR PUBLICATION JULY 15, 1958)

Twin studies have frequently been carried out by those interested in the causation of mental deficiency. Some of the work on this subject is summarized by Böök, Schut and Reed (1953). It is assumed that if the twins are monozygous then hereditary factors will be identical; it is often assumed that the intrauterine environment will likewise be identical. Though this may be true in general, there are important exceptions the study of which may throw light on the intra-uterine origin of abnormalities. Considerable differences in weight between 'identical' twins are well recognized. Penrose (1937) described syphilis in one of monovular twins and Hinden (1956) reported microcephaly in one of a monozygotic twin pair.

The object of this paper is to give an account of two more pairs of monozygous twins, one member of each pair being healthy, the other being mentally defective and having a head circumference within the microcephalic range. Microcephaly is here defined as a head circumference of less than three standard deviations from the mean for age and sex (Böök et al., 1953). The normal standards used are those of Westropp and Barber (1956).

\section{Case Reports}

Case 1. The father is a motor mechanic and the mother was a factory worker before marriage. They were aged 22 and 19 respectively at the birth of the patient and were in good health generally. The maternal great grandmother is said to have had two sets of twins, one being a blind child; a maternal aunt also has twins. The patient and his brother were the result of the first pregnancy, which, according to the hospital where the twins were born, lasted eight months. The mother is said to have had pneumonia at the fourth month and pyelitis at the sixth. The delivery was uneventful, the patient was born first. The mother was affected by eclampsia for several days after the delivery and has a blank in her memory for this period. The patient weighed $3 \mathrm{lb}$. $3 \mathrm{oz}$. and his skull circumference was 12 in.; the brother weighed $4 \mathrm{lb} .2 \mathrm{oz}$., but unfortunately his skull circumference was not measured. The placenta was noted to be uniovular in type and no further details are available from the hospital although the mother says that she understood that the patient's cord came from the side of the placenta whilst that of his brother was centrally attached.

The patient was slightly cyanosed at birth with bruising of the face, forehead, left shoulder, right wrist and some oedema of the lower limbs. Marked jaundice began on the second day lasting till the twenty-fourth, the serum bilirubin being $11 \mathrm{mg}$. \% on the ninth day. On the fifteenth day there was hiccuping but no neck rigidity or hypertonia although some twitching of the face was noted. Subsequent progress was described as satisfactory and the infant was discharged from hospital at the seventh week weighing $4 \mathrm{lb} .11 \mathrm{oz}$. The brother had

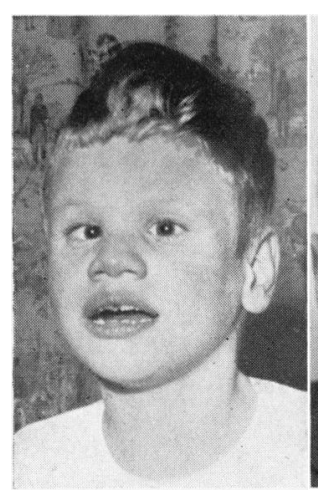

FIG. 1A.-Case 1. Microcephalic twin.

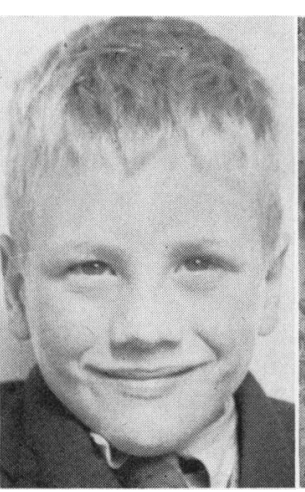

FIG. 18.-Normal twin.

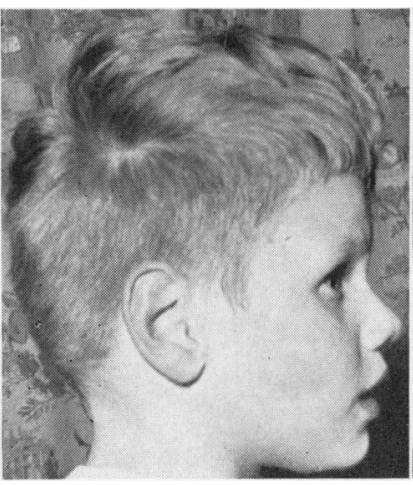

FIG. 2A.-Microcephalic twin.

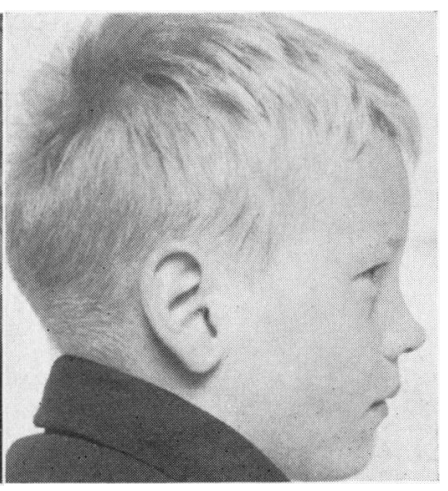

Fig. 2B.-Normal twin. 
some slight bruising of the vertex after delivery and developed a slight transient jaundice on the sixth day.

By contrast with his brother the patient failed to take notice and at 8 months when examined under anaesthetic was found to have optic atrophy, a finding which was confirmed at the age of 1 year. At 3 years he still did not walk and was thought at hospital not to have light perception. The small head was then noted. On admission to the Fountain Hospital aged 3 years and 4 months he was described as an imbecile with a developmental quotient of 22. The Vineland social maturity scale was used: this is very similar to a developmental scale at the early age ranges. He could see, followed objects with his eyes, but would not grasp them. He could not stand, walk or talk except to say 'Hallo'. His weight was $21 \mathrm{lb}$. and height $32 \frac{1}{2}$ in. The cranial circumference was $16 \frac{1}{2}$ in. $\left(41.9 \mathrm{~cm}\right.$.); the length $5 \frac{1}{2}$ in. $(14.0 \mathrm{~cm}$.); breadth 4 in. $(10 \cdot 2 \mathrm{~cm}$.); cranial index 0.73 .

He made little progress and at the age of 5 years and 9 months he could still only crawl and appeared almost blind with occasional nystagmus, scoring a social quotient of 13 (Figs. 1A and 2A). The head circumference at 7 years was $17 \frac{3}{4}$ in. $(45 \cdot 1 \mathrm{~cm}$.). The mean for boys of 7 years is $52.7 \mathrm{~cm}$. and the patient is between five and six standard deviations less than the mean for his age and sex in this respect. The head length is $6 \mathrm{in}$. and the breadth $4 \frac{5}{8}$ with a cranial index of $0 \cdot 77$.

The brother (Figs. 1B and 2B) is now a normal boy of 7 years with a vocabulary level of 9 years and an intelligence quotient of 108 on the Terman-Merrill scale, of 113 on the Progressive Matrices and of 116 on the Goodenough. The cranial circumference is 20 in. $(50.8 \mathrm{~cm}$.) which is between one and two standard deviations below the mean for his age and sex. The length of the head is $18 \cdot 1 \mathrm{~cm}$. (7 1/10 in.); the breadth is $13.5 \mathrm{~cm}$. ( $53 / 10 \mathrm{in}$.); the cranial index 0.75 .

He presents no physical or mental abnormalities.

The twins were noted to be very similar at birth and at the present time, despite the difference in head size, they look very like each other, they have the same blue eyes and hair colour. The blood groups of the family are as follows:

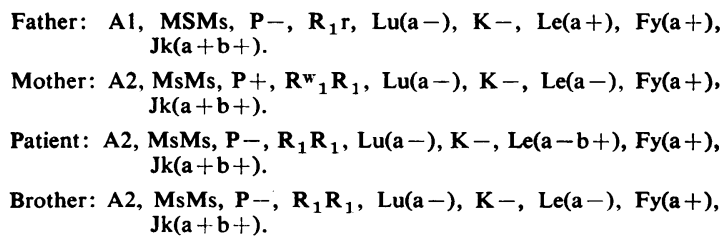

Dr. Ruth Sanger concluded on the basis of these results that the probability of dizygosity was $0 \cdot 76 \%$. Palm prints of the twins were also studied and the patterns on the fingers were in agreement. The palmar patterns were not very similar superficially but the difference in the sum of the Atd angles was only 4 degrees. Combining the two sets of data Professor Penrose concluded that the probability of dizygosity was $0 \cdot 213 \%$, i.e. $1 / 476$. The present measurements of the twins are set out as follows:

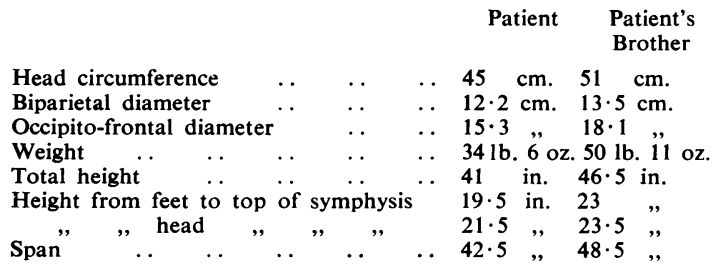

Case 2. The father is an engineer and the mother was a dressmaker before marriage; they were aged 35 and 33 respectively at the patient's birth. There is no report of any mental or physical defect, mental illness or fits in the family and the parents are in good health. The patient and her twin sister were the result of the fifth pregnancy. The first child was stillborn and is said to have been 'strangled by the cord' and to have weighed $8 \mathrm{lb}$. The second was also stillborn at 7 months and there was said to have been no movement for three months prior to the delivery. The mother is said to have had toxaemia during that pregnancy. The third and fourth pregnancies resulted in normal boys, the former of whom weighed $10 \mathrm{lb} .7 \mathrm{oz}$. The mother was well during the twin pregnancy but suffered from swollen feet towards term. Labour was precipitate and occurred at home whilst the mother was sitting on a chair. The first and normal twin was born as the water broke and the patient 'shot out' 10 minutes later. She was taken to hospital because she did not cry and she was put into an oxygen tent. The birth weight was $4 \mathrm{lb} .10 \mathrm{oz}$. The baby was said to have fallen on the floor when she was born. She was admitted to a premature unit where she was found to be collapsed and to show signs of ' cerebral irritation'. There were episodes of twitching during the first 4 days of life and she had to be fed by oesophageal tube for the first 10 days. Her progress was satisfactory as far as feeding went but when seen at a year she was a microcephalic idiot. She could not sit, could not feed herself, there were repetitive movements and she seemed unable to focus. The birth weight of the normal twin was $7 \mathrm{lb}$. No difficulty was experienced with her during the post-natal period and she weighed $8 \mathrm{lb} .3 \mathrm{oz}$. when discharged from hospital.

The patient was seen again in hospital at 16 months for examination of the eyes under anaesthesia. Both discs were pale but not definitely pathological. There was a right internal strabismus and the head circumference was $15 \frac{3}{4}$ in. $(40.0 \mathrm{~cm}$.). She could still not sit up, was definitely backward and there was no evidence of cerebral palsy. The normal twin appeared very much like the patient apart from the shape of the head, which in her case measured 18 in. in circumference.

The child was first admitted to the Fountain Hospital at 28 months. She weighed $22 \mathrm{lb}$. and the height was $33 \frac{1}{2}$ in.; cranial circumference $16 \frac{1}{2}$ in. $(41.9 \mathrm{~cm}$.); length 5 in. $(12.7 \mathrm{~cm}$.$) ; breadth 4$ in. $(10 \cdot 2 \mathrm{~cm}$.); cranial index $0 \cdot 80$. She frequently assumed an opisthotonic position. She could not assume or maintain the sitting position. She could not stand, walk, talk or feed herself. She was spoon-fed with difficulty and could not chew. She did not appear blind and seemed to fix objects, 


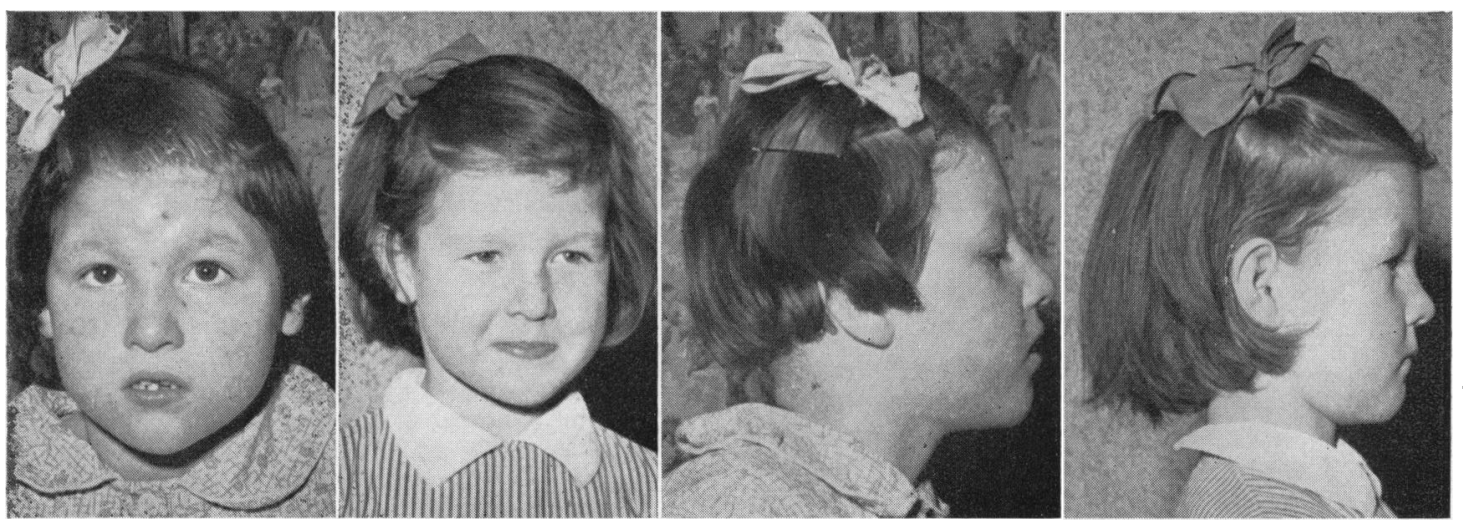

FIG. 3A.-Case 2. Microcephalic twin.

FIG. 3B.-Normal twin.

FIG. 4A.-Microcephalic twin.

FIG. 4B.-Normal twin.

though her squint made assessment of this difficult. She smiled when a bell was rung, but she made no attempt to take objects. Her social quotient on the Vineland scale was then 9 .

Very little progress was made and when the child was examined at the age of 6 years, the quotient on the same scale was 10 which was almost identical (Figs. 3A and 4A). Although interested and responsive she would only grasp toys when they touched her hand and retained them for only a few seconds. She could not stand, walk or talk and could not feed herself. She was doubly incontinent. Two major epileptic fits had been recorded during the last year. The head circumference was $17 \frac{5}{8}$ in. $(44.8 \mathrm{~cm}$.). The mean for girls of 6 years is $51.7 \mathrm{~cm}$. and the patient is between four and five standard deviations less than the mean for her age and sex in this respect. The head length is $5 \frac{5}{8} \mathrm{in} .(14 \cdot 3 \mathrm{~cm}$.), and the breadth $4 \frac{5}{8}$ in. $(11 \cdot 7 \mathrm{~cm}$.), with a cranial index of 0.82 .

The sister (Figs. 3B and 4B) is now a normal girl of 6 years with a good vocabulary and memory for verbal items. She achieved a score of 109 on the Terman-Merrill scale and of 112 on the Goodenough 'draw a man' test. She is considered above average in ability. The cranial circumference is 20 in. $(50.8 \mathrm{~cm}$.) which is within the standard deviation from the mean for her age and sex. The length of the skull is $67 / 10$ in. $(17.0 \mathrm{~cm}$.) and the breadth $53 / 10 \mathrm{in}$. $(13.5 \mathrm{~cm}$.$) , cranial$ index $0 \cdot 79$. She presented no physical or mental abnormalities, apart from a contracture of the little finger which she has in common with the patient.

Although the twins were similar in other respects the patient was distinguished from birth by her oddly shaped head which was flat at the back and had a sloping forehead, also by her slow development. The eye colour appears identical but the normal girl's hair is fairer with blond streaks in front (? influence of extraneous factors). The blood groups of the family are as follows:

Father: $\mathbf{B}, \mathbf{M S M s}, \mathbf{P}+, \mathbf{R}_{\mathbf{1}} \mathrm{r}, \operatorname{Lu}(\mathrm{a}+), \mathrm{K}-\operatorname{Le}(\mathrm{a}-), \mathrm{Fy}(\mathrm{a}-)$, Jk(a+).

Mother: O, MSNs, P-, $\mathbf{R}_{1} \mathbf{R}_{2}, \operatorname{Lu}(\mathrm{a}-), \mathrm{K}-, \operatorname{Le}(\mathrm{a}+\mathrm{b}-), \mathrm{Fy}(\mathrm{a}+)$, Jk(a-).
Patient: $\mathbf{O}, \operatorname{MsNs}, \mathbf{P}+, \mathbf{R}_{1} \mathbf{R}_{1}, \operatorname{Lu}(\mathrm{a}-), \mathrm{K}-, \operatorname{Le}(\mathbf{a}-), \operatorname{Fy}(\mathrm{a}-)$, $\mathbf{J k}(\mathbf{a}+\mathbf{b}+)$

Sister: $\mathbf{O}$, MsNs, $\mathbf{P}+, \mathbf{R}_{1} \mathbf{R}_{1}, \operatorname{Lu}(\mathbf{a}-), K_{-}, \operatorname{Le}(\mathbf{a}-), \operatorname{Fy}(\mathbf{a}-)$, Jk $(a+)$.

Dr. Ruth Sanger who kindly provided this information estimated the chance of dizygosity as $0.40 \%$, i.e. $1 / 250$. This was improved by Professor Penrose to $0.25 \%$, i.e. $1 / 400$, by consideration of finger ridge counts and atd angles.

\section{Discussion}

From the evidence presented it may reasonably be assumed that these two twin pairs were each identical. One child in each pair is both mentally defective and microcephalic.

In Case 1 there was some evidence of birth trauma in the affected twin. In this case, however, the child's head was already $3 \cdot 5$ standard deviations below the mean at birth. This is a greater reduction than might be expected merely because of prematurity. This child also had jaundice, but the serum bilirubin, though raised to $11 \mathrm{mg}$. $\%$, did not reach the critical level of $18 \mathrm{mg}$. \% (Crosse, Meyer and Gerrard, 1955) at which kernikterus is likely to ensue, nor was transfusion required. Optic atrophy, which was present in this case, has not, in our experience, been a feature of the post-kernikteric syndrome (Crome, Kirman and Marrs, 1955).

In Case 2 the affected twin was distinguished by her flattened occiput and sloping forehead. The head circumference at 16 months was $40.0 \mathrm{~cm}$., which corresponds to the mean for a 3-month-old baby and is more than four standard deviations below the mean for age and sex. Despite the history of precipitate labour and neonatal distress, it is improbable that such a reduction in size was due solely to birth injury.

The balance of the evidence, therefore, in both cases, favours the view that the microcephaly was 
due to factors operating during pregnancy, though it is admittedly difficult to exclude 'birth injury' in the broad sense of the term, as a causal factor.

Since, in each case, the other twin is normal it becomes difficult to assign the defect to the influence of hereditary factors, although there is a strong tendency to do this in regard to microcephaly. Indeed Komai, Kishimoto and Ozaki (1955) state that 'the evidence for the production of microcephaly by non-genetic agents other than irradiation is not convincing'. There is no history of irradiation in these two cases and it seems difficult to escape the conclusion that the small size of the head is due to unknown adverse factors operating during pregnancy.

The potentially adverse effects of twinning may be considered as a factor in these cases. It is well recognized that twins tend to have a low birth weight and are more subject to the hazards which beset premature infants. There is also a certain association between very low birth weights and congenital abnormality. Thus, in cases of rubella embryopathy (Director-General Public Health Services, New South Wales, 1945) the birth weight is low, averaging $5 \mathrm{lb} .15 \mathrm{oz}$. in 130 cases. In 99 cases of microcephaly at the Fountain Hospital the average birth weight was $6 \mathrm{lb} .1 \mathrm{oz}$. It may be argued that in, for example, genetically determined cases of microcephaly it is the brain defect which produces the smallness of the foetus. On the other hand, in cases such as those reported here it may be that adverse factors, including multiple pregnancy, tend to produce both low birth weight and brain defect.

Certain difficulties of definition arise in considering this problem. If a baby has a low birth weight, then is it correct to assess the head size on the basis of standards derived from babies most of whom had a normal birth weight? Experience suggests that, although this procedure may seem illogical, it will afford a rough guide as to the baby's prospect of normal development and that a marked reduction below the norm indicates a probability of permanent microcephaly.

A related problem concerns the definition of 'true' microcephaly which is usually equated with forms of the condition which are thought to be genetically determined. A critique of the concept of 'true' microcephaly is contained in a separate communication. Although many authors suggest that it is possible to recognize the condition clinically there is little general agreement on the signs although long-headedness ('Aztec form') is the one on which there is best accord. The cranial index in the present cases was 73 and 77 in Case 1 and 80 and 82 in Case 2. These measurements compare with Penrose's (1954) figure of 73, being an average for 10 cases of microcephaly, a figure which is in the dolichocephalic range. The present cases therefore do not provide evidence against the view that genetic cases of microcephaly can be distinguished by dolicocephaly.

\section{Summary}

Two pairs of uniovular twins are described. In each case one member of the pair was microcephalic and the other normal. The cause of the abnormality was not apparent from the history but appears to have been operative during pregnancy. These cases suggest that $\epsilon$ nvironmental causes of microcephaly may be important in the absence of a history of irradiation or rubella.

\section{REFERENCES}

Böök, J. A., Schut, J. W. and Reed, S. C. (1953). Amer. J. ment. Defic., 57, 637 .

Crome, L., Kirman, B. H. and Marrs, M. (1955). Brain, 78, 514. Crosse, V.'M., Meyer, T. C. and Gerrard, J. W. (1955). Arch. Dis.

Director-General Public Health Services, N.S.W. (1945). Med. J. Aust., 2, 122

Hinden, E. (1956). Brit. med. J., 1, 333.

Komai, T., Kishimoto, K. and Ozaki, Y. (1955). Amer. J. hum. Genet., 7, 51 .

Penrose, L. S. (1937). Lancet, 1, 322.

(1954). The Biology of Mental Defect, 2nd ed., pp. 84 and 134 Sidgwick and Jackson: London

Westropp, C. K. and Barber, C. R. (1956). J. Neurol. Neurosurg. Psychiat., 19, 52. 